\title{
Abnormal Expansion of Cu-Sn Powder Compacts During Sintering*
}

\author{
By Hiroyasu Mitani**
}

\begin{abstract}
It is well known that an abnormal expansion appears in $\mathrm{Cu}$-Sn compacts during sintering. In order to investigate the source of this phenomenon, the author carried out a dilatometric study on the kinetics of sintering for $\mathrm{Cu}-\mathrm{Sn}$ compacts containing about $10 \% \mathrm{Sn}$ powder and $0.5 \% \mathrm{Zn}$-stearate as lubricant.

In this experiment the abnormal expansion always appeared at $798^{\circ} \mathrm{C}$, which is the highest peritectic temperature in the $\mathrm{Cu}$-Sn system, and increased in amount with the increase of the heating rate. From the microscopic examination, it was found that just below the peritectic temperature a large amount of the liquid phase was retained in the compact coexisting with the $\beta$ phase. However, just at this temperature or above the $\beta$ phase should decompose into $\alpha$ phase and liquid phase, accelerating the diffusion rate and the following solidification.

In this way absorbed gases in the liquid phase of the compact were discharged by rapid solifidication at the peritectic temperature during sintering, a great portion of the absorbed gases can be estimated as $\mathrm{H}_{2}$ from the atmosphere controlling examination. In order to eliminate the abnormal expansion, slow heating, isothermal keeping just below the peritectic temperature and the reduction of the $\mathrm{Sn}$-content in the compact are recommended.
\end{abstract}

(Received December 24, 1962)

\section{Introduction}

On sintering for pure $\mathrm{Cu}$ powder compact, its porosity decreases with increase of sintering temperature, after coolng to room temperature the sintered $\mathrm{Cu}$ compact shrinks corresponding to its porosity. However, volume expansion can be seen during sintering above $800^{\circ} \mathrm{C}^{(1)}$, depending on the compacting pressure (2) and sintering atmosphere ${ }^{(3)}$. It is presumed that this sintering expansion originates in the gases, which produce an effect only on the solid $\mathrm{Cu}$ particles.

Fabricating the $\mathrm{Cu}-\mathrm{Sn}$ powder sintered bearing, causes an abnormal expansion to appear which interferes with the fabrication. In this case the interaction between the gas, the liquid and the solid must be concerned, hence the reaction phenomena should be more complicated than that of the pure $\mathrm{Cu}$ powder compact mentioned above. In order to prevent this cumbrous abnormal expantion, it is necessary to investigate the causes.

\section{Experimental Procedure}

Powders were prepared as follows; 80 mesh electrolytic $\mathrm{Cu}$ powder reduced by hydrogen at $430^{\circ} \mathrm{C}$ for $1 \mathrm{hr}, 200$ mesh atomized Sn powder for the alloying element and $\mathrm{Zn}$-stearate as the powder lubricant were provided for compacting. Well mixed power of $90 \%$ $\mathrm{Cu}$ and $10 \% \mathrm{Sn}$ containing $0.5 \% \mathrm{Zn}$-stearate were compacted into a rectangular shape of $60 \mathrm{~mm} \times 20 \mathrm{~mm}$ $\times 8 \mathrm{~mm}$ with an apparent density of 6.50 to 6.55 under $2 \mathrm{ton} / \mathrm{cm}^{2}$ at room temperature. These preparation were made by the Sumitomo Electric Ind. Ltd.

Specimens provided in this experiment were cut

* This paper was published in the Journal of the Japan Society of Powder Metallurgy, 8 (1961), 43.

** Department of Metallurgy, College of Engineering, University of Osaka Prefecture, Sakai, Osaka, Japan.

(1) J. E. Drapeau: Powder Metallurgy, (ASM), (1942), 323.

(2) W. Trzebiatowski: Z. Phys. Chem., B24 (1934), 75.

(3) A. I. Shaler and J. Wulff: Ind. Eng. Chem., 40 (1948), 838. out from the rectangular compacts into cylindrical shape of $5 \mathrm{~mm} \phi \times 20 \mathrm{~mm}$ respectively. Fig. 1 and Fig. 2 show the equipment used for the dilatometric experiment, where the scale reading was magnified

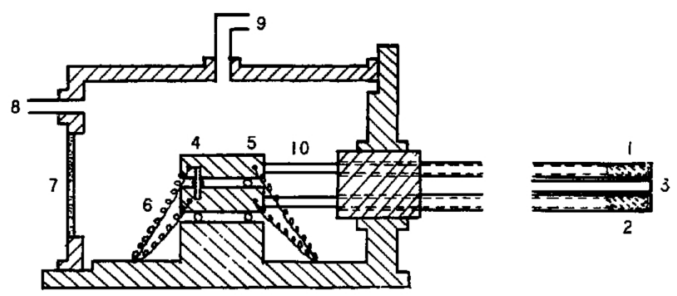

Fig. 1 Differential dilatometer.
1. Specimen
4. Mirror
7. Glass plate
2. Neutral
5. Roller
8. Gas inlet
3. Thermocouple 6. Spring
9. Gas exit
10. Silica rod

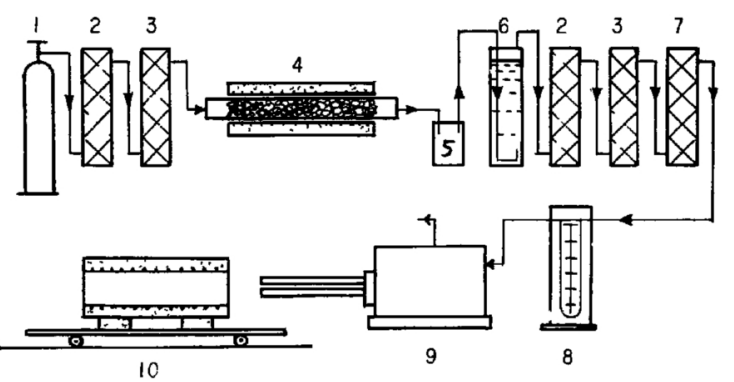

Fig. 2 Apparatus.
1. $\mathrm{NH}_{3}$ cylinder
2. $\mathrm{NaOH}$ tower
6. $\mathrm{NH}_{3}$ absorption tower
3. Soda lime tower
7. $\mathrm{P}_{2} \mathrm{O}_{5}$ tower
4. Cracking furnace
5. Safety bottle
8. Flowmeter
9. Dilatometer
10. Heating furnace

about 400 times the real dilatational change. Cast bronze containing about $10 \% \mathrm{Sn}$ of the same size as described above was used as a neutral specimen for the differential measurement. A test piece and the neutral specimen fixed in two separate silica tubes were heated in an non-oxidizing atmosphere of anhydrous cracked ammonia produced by a cracking 
furnace at $850^{\circ} \mathrm{C}$ using Ni-nitrate as an active catalyst. The flow rate of the cracking gas was $200 \mathrm{cc} / \mathrm{min}$, which was sufficient to keep the gastight container in an non-oxidizing condition.

\section{Experimental Results}

1. Influence of heating rate on the abnormal expansion

The differential dilatometric experiments were carried out at the heating rate of $20^{\circ} \mathrm{C} / \mathrm{min}, 10^{\circ} \mathrm{C} / \mathrm{min}$, $5^{\circ} \mathrm{C} / \mathrm{min}$ and $2.5^{\circ} \mathrm{C} / \mathrm{min}$ respectively. The results obtained are illustrated in Fig. 3. All the dilatation curves likewise show that the specimens gradually contract with increasing temperature up to $798^{\circ} \mathrm{C}$.

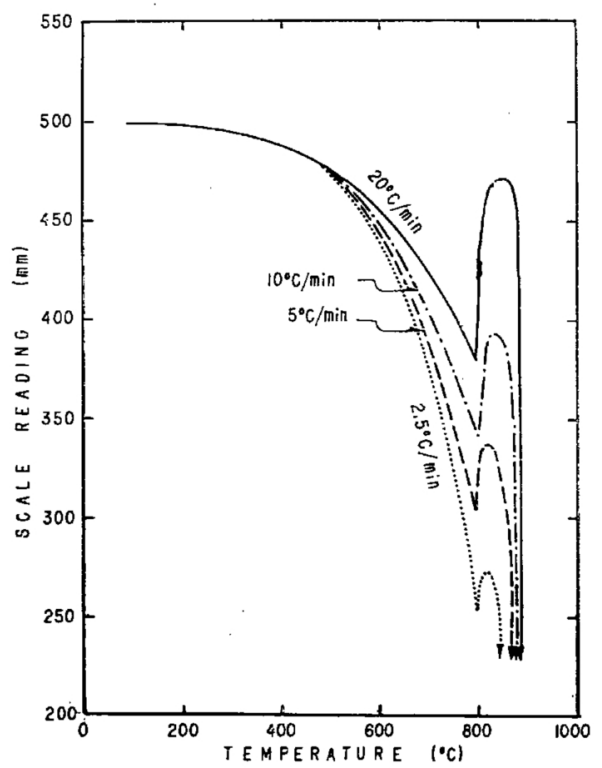

Fig. 3 The effect of the heating rate upon the differential dilatometric curve for $\mathrm{Cu}-\mathrm{Sn}$ compacts containing about $10 \% \mathrm{Sn}$

This contraction indicates the proceeding of sintering, where the amount of contraction decreases with an increase of the heating rate. However, independent of the heating rate, a conspicuous expansion is found

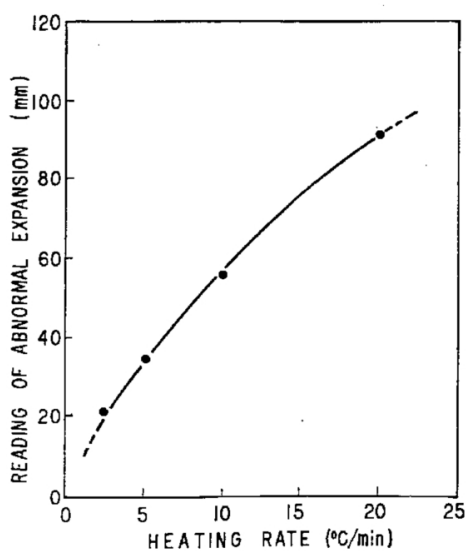

Fig. 4 Abnormal expansion vs. heating rate.

at $798^{\circ} \mathrm{C}$ in every dilatation curve. When the scale reading of height between the valley and the peak of the dilatation curve is assumed as the amount of the abnormal expansion, it increases parabolically against the heating rateas as shown in Fig. 4, where only one directional change of the specimen is given, therefore it is necessary to check whether the volume change corresponds to the dilatational change of the specimen.

From this point of view, the same specimens were heated at the rate of $20^{\circ} \mathrm{C} / \mathrm{min}$ respectively in the same manner as mentioned above, where the heating was interrupted halfway by removing the furnace, thereafter all the specimens were air-cooled. Fig. 5 shows these cooling curves by a broken line. The relationship between the final readings at the room temperature and heating temperatures also can be shown with a chain line in Fig. 5, establishing an identical process with the original dilatation curve of

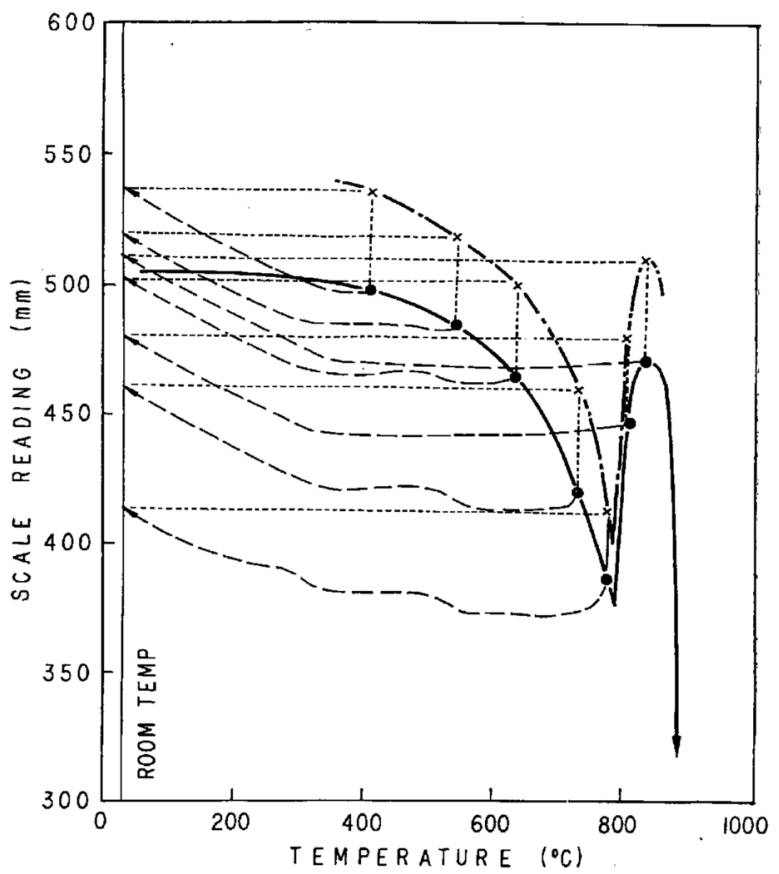

Fig. 5 A plot of the dilatometric after effect retained at room temperature.

shown by a full line. Independent of the cooling process, the dilatational change remains after cooling

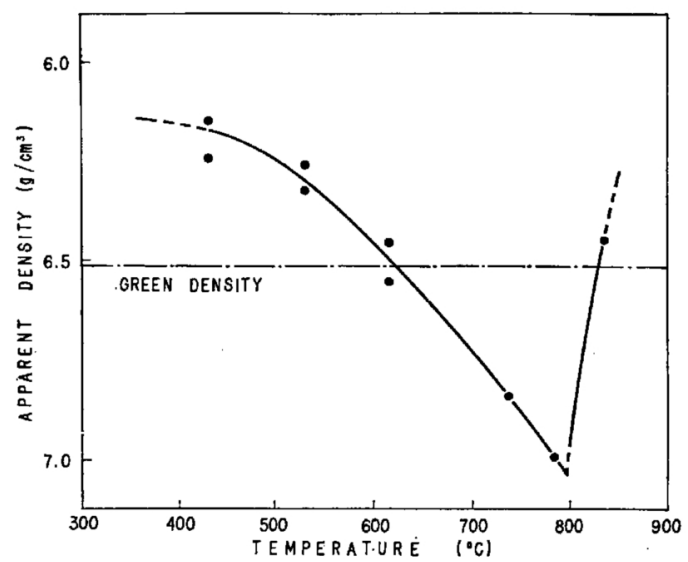

Fig. 6 The apparent density vs. the maximum heating temperature for specimens as prepared in Fig. 5.

down to the room temperature.

Since the volume change of a sintered specimen should be in inverse proportion to the apparent density, the former can be expressed from a recipocal 
of the latter. When the apparent density of the specimen obtained under the same conditions of heating and cooling as mentioned above is plotted in relation to the heating temperature in Fig. 6, the curve in this figure is quite similar to the chain line curve shown in Fig. 5. Consequently it can be confirmed that the volume change of the sintered specimen corresponds to the dilatational change. Finally it has been proven that the dilatation curve exactly and continuously represents the volume change during compact sintering.

\section{Examination close to the abnormal expan- sion temperature}

The differential dilatation curves of the specimens, which were heated at a constant rate of $20^{\circ} \mathrm{C} / \mathrm{min}$ up to the $788^{\circ} \mathrm{C}, 798^{\circ} \mathrm{C}$ and $808^{\circ} \mathrm{C}$ respectively and kept isothermally at these temperatures, are shown in Fig. 7. In spite of isothermal keeping for a long time at $788^{\circ} \mathrm{C}$, no expansion appears, but continuous contraction follows with time. However, both at $798^{\circ} \mathrm{C}$ and $808^{\circ} \mathrm{C}$ the abnormal expansions appear respectively,

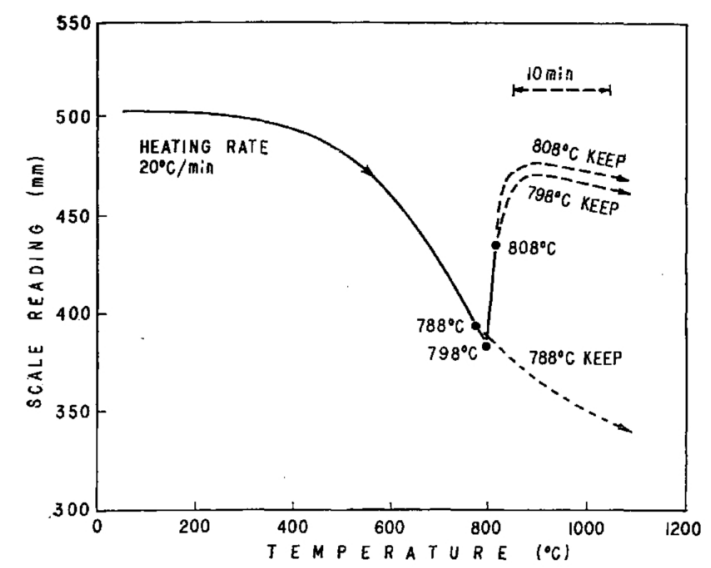

Fig. 7 The isothermal dilatometric change close to the peritectic temperature.

and never disappear with subsequent isothermal heating. Consequently, the abnomal expansion is an unavoidable phenomenon above $798^{\circ} \mathrm{C}$ for sintering of the $\mathrm{Cu}-\mathrm{Sn}$ compacts. It reveals the fact that the abnormal expansion starts always at $798^{\circ} \mathrm{C}$ constant independent of the heating rate. Below this temperature it never appears no matter how long it may be kept isothermally, and this temperature seems to be connected with the highest peritectic temperature of $798^{\circ} \mathrm{C}$ in the $\mathrm{Cu}-\mathrm{Sn}$ equilibrium diagram.

From this point of view, casting specimens of $20 \%$ Sn containing $\mathrm{Cu}-\mathrm{Sn}$ binary alloy shaped into the same size as described before were used for the dilatometric experiment, where the heating rate was $3^{\circ} \mathrm{C} / \mathrm{min}$ and the scale reading of dilatation was 4000 magnification.

The dilatation curves for the specimens as cast and annealed are shown in Fig. 8. Each of the curves shows first a small contraction identical to the lower eutectoid temperature of $520^{\circ} \mathrm{C}$ and a abrupt contraction in accordance with the highest peritectic temperature of $798^{\circ} \mathrm{C}$ in the $\mathrm{Cu}$-Sn binary system. However, any other change of expansion can be found in this experiment.
Censequently it can be confirmed that the abnormal expansion during the sintering of $\mathrm{Cu}-\mathrm{Sn}$ compacts does not exhibit the peritectic reaction itself but a following phenomenon actuated by the peritectic reaction.

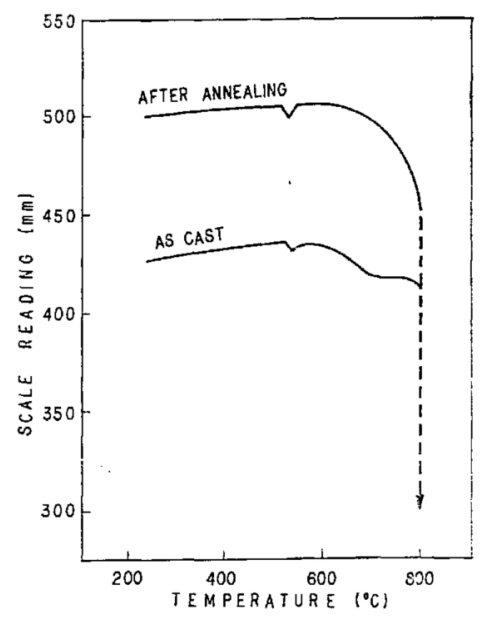

Fig. 8 Dilatometric curves for cast bronze specimens containing about $20 \% \mathrm{Sn}$, prepared by heating at the rate of $3^{\circ} \mathrm{C} / \mathrm{min}$. (magnification 4000 )

In order to confirm the above described experiments microscopic examinations were carried out. Procedure of this examination was as follows: a specimen fixed in the dilatometer was heated at a constant rate of $20^{\circ} \mathrm{C} / \mathrm{min}$. As soon as the specimen reached a given temperature, the heating furnace was rapidly removed and the specimen fixed in the silica tube was rapidly cooled by a water-jet. Photos. 1, 2 and 3 show in turn the microstructures of the specimens quenched from $788^{\circ} \mathrm{C}, 798^{\circ} \mathrm{C}$ and $808^{\circ} \mathrm{C}$ respectively, where Grard solution was used for the etching reagent.

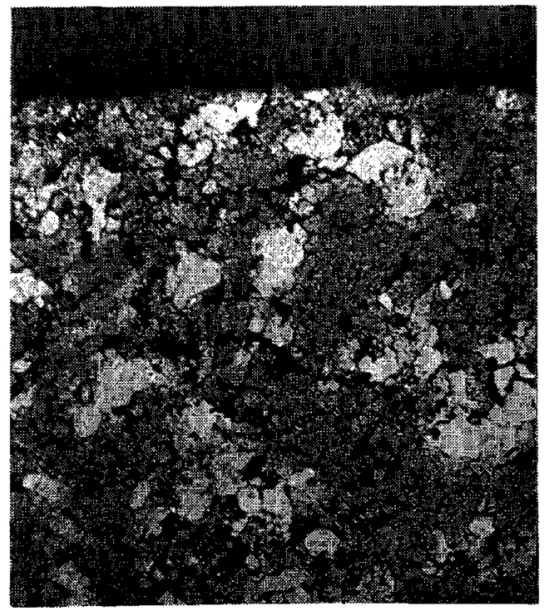

Photo. 1 Rapid cooling from $788^{\circ} \mathrm{C} . \quad(\times 100)$

Generally speaking, the shallow etching regions consist of $\mathrm{Cu}$, while the white regions are an Sn rich alloying phase, and the dark parts show pores, which increase and grow abruptly at $798^{\circ} \mathrm{C}$ as shown in Photo. 2. The pores connect with one another as if the absorbed gas were exhausted out through them as shown in Photo. 3. It is characteristic that the pores always appear in the $\mathrm{Sn}$ rich regions.

The weight percentage of the $\mathrm{Cu}$ region in Photos. 1,2 and 3 can be easily calculated by the point count- 
ing method ${ }^{(4)}$. The obtained results amount to about 60,30 and $15 \%$ in turn, and the balancing percentages of 40,70 and 85 can be estimated as the weight fractions of the alloying region in Photos. 1, 2 and 3 respectively.

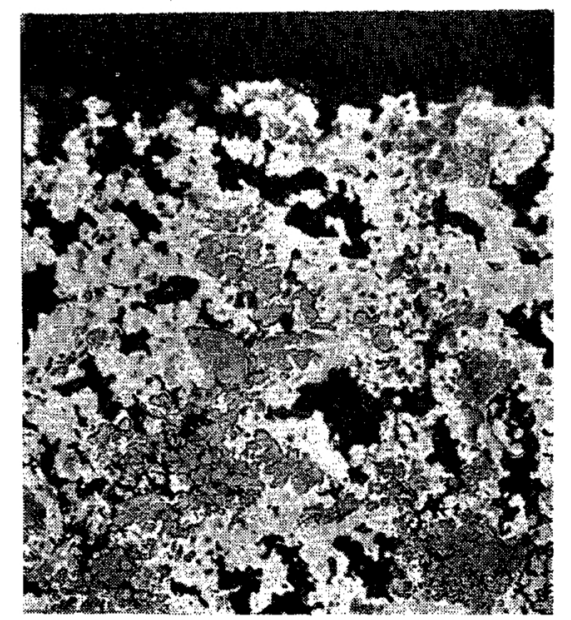

Phsto. 2 Rapid cooling from $798^{\circ} \mathrm{C} .(\times 100)$

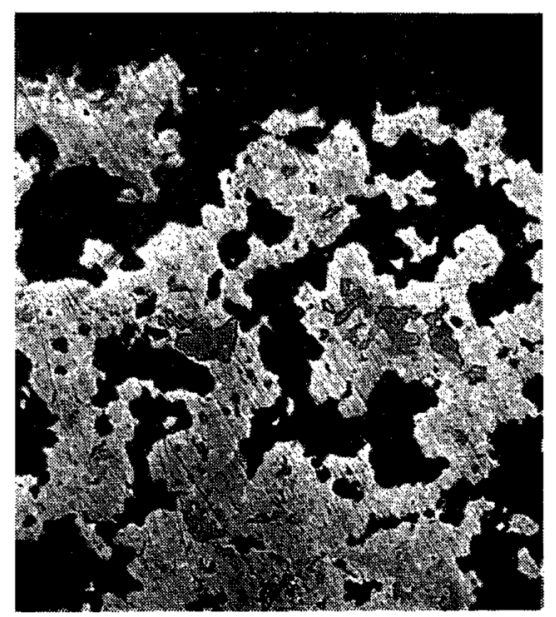

Photo. 3 Rapid cooling from $808^{\circ} \mathrm{C} .(\times 100)$

Assumed the equilibrium state to exist in the alloying regions, Sn contents in them can be easily calculated, since the initial composition of the green compact was $90 \% \mathrm{Cu}$ and $10 \% \mathrm{Sn}$. In this manner temperature of $798^{\circ} \mathrm{C}$ it decreases to $7 \%$ and completely disappears at $808^{\circ} \mathrm{C}$, while the liquid phase coexists with the $\beta$ phase below this temperature. The existence of $\beta$ has not yet directly confirmed in the sintered specimens.

\section{Dissolution of solid $\mathrm{Cu}$ into molten $\mathrm{Cu}-\mathrm{Sn}$ alloys}

In order to confirm the results of microscopic examination, the dissolution rate of $\mathrm{Cu}$ into molten $\mathrm{Cu}-\mathrm{Sn}$ alloys was investigated in the following way.

Specimens of $\mathrm{Cu}$ wire were $3 \mathrm{~mm} \phi \times 200 \mathrm{~mm}$. $1 \mathrm{~kg}$ of three $\mathrm{Cu}-\mathrm{Sn}$ alloys, which contain $38.65 \%, 34.65 \%$ and $30.00 \% \mathrm{Sn}$ respectively, were melted in a graphite crucible at the temperature range between $780^{\circ} \mathrm{C}$ and $820^{\circ} \mathrm{C}$. In the molten alloy the $\mathrm{Cu}$ wire specimen was dipped down to a depth of $50 \mathrm{~mm}$, and kept isothermally for a given time. As soon as the isothermal treatment of dissolution was finished, the specimen was quenched in water. The diameter of specimen was measured before and after treatment.

Suppose the initial diameter $D_{0}$ and the final diameter $D$, dissolution-depth of the specimen can be

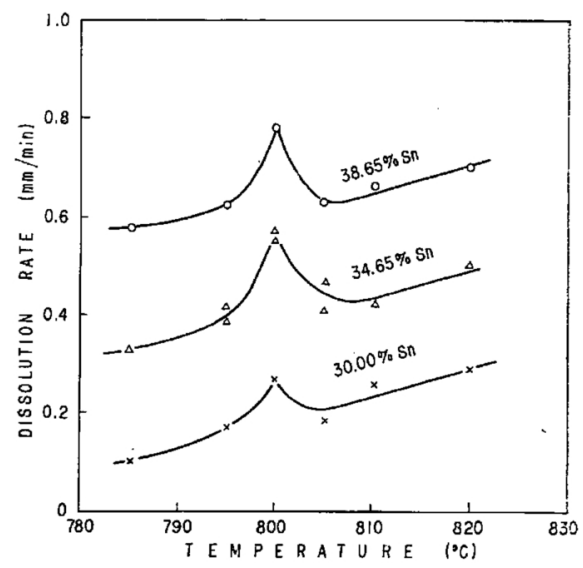

Fig. 9 The dissolution rate of $\mathrm{Cu}$ in a molten $\mathrm{Cu}-\mathrm{Sn}$ alloy bath.

written as $\left(D_{0}-D\right) / 2$. Since the results of this dissolution experiment showed a straight line relationship between the dissolution-depth and -time, the dissolution rate $R$ is given by :

Table 1 Compositions and phases in the alloying regions of the sintering specimens in relation to the heating temperature at a constant heating rate of $20^{\circ} \mathrm{C} / \mathrm{min}$.

\begin{tabular}{|c|c|c|c|c|c|c|}
\hline \multirow{2}{*}{ Temp. } & \multirow{2}{*}{$\begin{array}{l}\text { Observed ratio } \\
\text { alloy } / \mathrm{Cu}\end{array}$} & \multirow{2}{*}{$\begin{array}{l}\text { Calculated } \mathrm{Sn} \% \text { in } \\
\text { the alloying region }\end{array}$} & \multicolumn{4}{|c|}{$\begin{array}{l}\text { Phases in the alloying regions referred } \\
\text { to the } \mathrm{Cu}-\mathrm{Sn} \text { equilibrium diagram }\end{array}$} \\
\hline & & & Liquid $(\%)$ & $\beta(\%)$ & $\alpha(\%)$ & $\mathrm{Cu}(\%)$ \\
\hline $788^{\circ}$ & $40 / 60$ & 25.0 & 27 & 13 & 一 & 60 \\
\hline $798^{\circ}$ & $70 / 30$ & 14.3 & 7 & - & 63 & 30 \\
\hline $808^{\circ}$ & $85 / 15$ & 11.7 & - & - & 85 & 15 \\
\hline
\end{tabular}

also the phases in the alloying regions at a given temperature can be quantitatively determined referring to the $\mathrm{Cu}-\mathrm{Sn}$ equilibrium phase diagram. The data thus obtained is shown in Table 1.

From this Table the fraction of the liquid phase amounts to $27 \%$ at $788^{\circ} \mathrm{C}$. However, at the peritectic

(4) E. S. Machlin and M. Cohen: Trans. AIME., 172 (1947), 413.

$$
R=\left(D_{0}-D\right) / 2 t,
$$

where $t$ is the isothermal dipping time in minutes, and the plot of the dissolution rate against temperature are shown in Fig. 9, in which peaks of the dissolution rate can be seen constantly at $800^{\circ} \mathrm{C}$ near the peritectic temperature. Consequently it is confirmed that the dissolution of $\mathrm{Cu}$ in the molten $\mathrm{Cu}-\mathrm{Sn}$ alloys increases remarkablly at this temperature. 
Such a phenomenon as described above can be seen also in hot galvanizing ${ }^{(5)}$. In this case it is well known that the dissolution of $\mathrm{Fe}$ in molten $\mathrm{Zn}$ is maximum at $495^{\circ} \mathrm{C}$, which is the lowest peritectic temperature of the $\mathrm{Zn}-\mathrm{Fe}$ binary system. However, it has not yet explained for what reason the dissolution is accelerated by the peritectic reaction.

In this point of view, the following experiment was carried out. The extruded $\mathrm{Cu}$ specimens $20 \mathrm{~mm} \phi \times$ $25 \mathrm{~mm}$ were used for this experiment. A hole $5 \mathrm{~mm} \phi$ $\times 20 \mathrm{~mm}$ was bored in the center of the $\mathrm{Cu}$ specimen and repleted with molten Sn of $99.9 \%$. Another hole $4 \mathrm{~mm} \phi \times 10 \mathrm{~mm}$ was bored in an eccentric position of the same specimen for temperature measurement.

A specimen was placed in an electric furnace preheated to $780^{\circ} \mathrm{C}$. After the temperature of the specimen reached $780^{\circ} \mathrm{C}$, the specimen was kept isothermally at this temperature for a given time, and finally quenched in water.

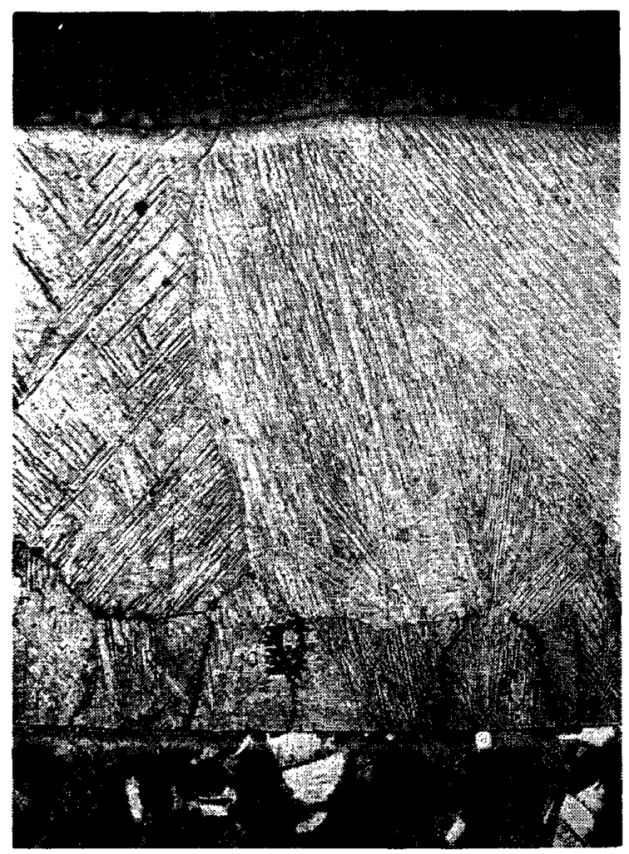

Photo. $4 \mathrm{Cu}-\mathrm{Sn}$ diffusion couple, $780^{\circ} \mathrm{C}$ for $1 \mathrm{hr}$ then quenched.

$(\times 100)$

The microstructure of the quenched specimen, which was kept isothermally at $780^{\circ} \mathrm{C}$ for 1 hour, is shown in Photo. 4, where the three phases of $\alpha$ (almost $\mathrm{Cu}$ ),

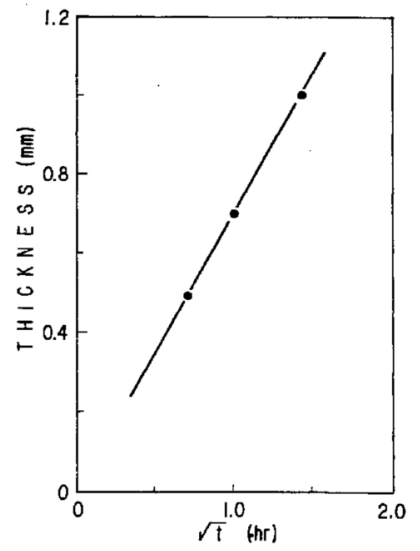

Fig. 10 The growth of the $\beta$ phase at $780^{\circ} \mathrm{C}$.

( 5 ) E. Scheil u. H. Wurst : Z. Metallkunde, 29 (1937), 224. $\beta$ (acicular structure of $\beta^{\prime}$ martensite) and liquid. (dendritic structure) can be seen layer by layer. So far as the peritectic reaction is concerned, only the $\beta$. phase should be examined. Plot the growth of the $\beta$. phase layer against the square root of the isothermal keeping time, and a linear relationship (parabolic law of diffusion) can be obtained, as shown in Fig. 10.

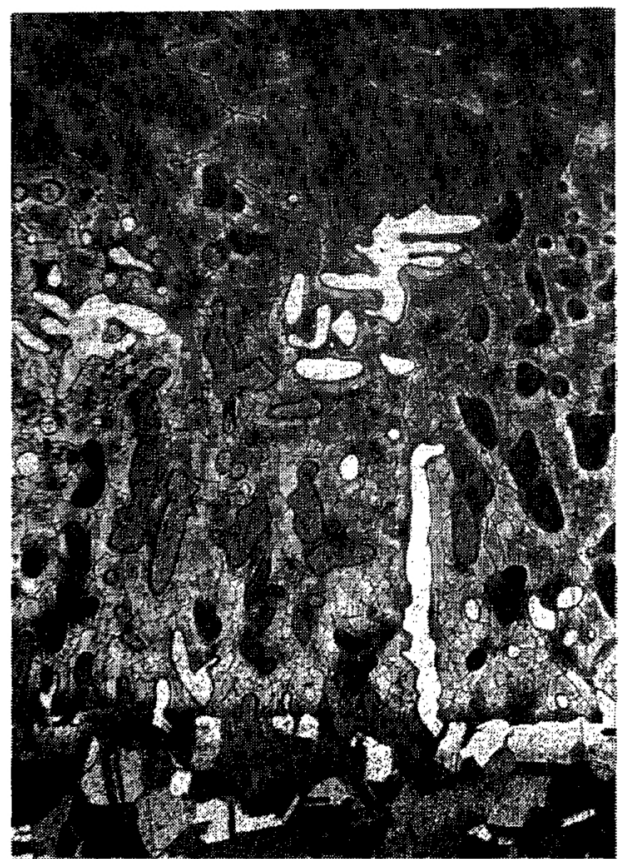

Photo. $5 \mathrm{Cu}-\mathrm{Sn}$ diffusion couple, $780^{\circ} \mathrm{C}$ for $1 \mathrm{hr}$ then reheated to $798^{\circ} \mathrm{C}$ and quenched. $(\times 100)$.

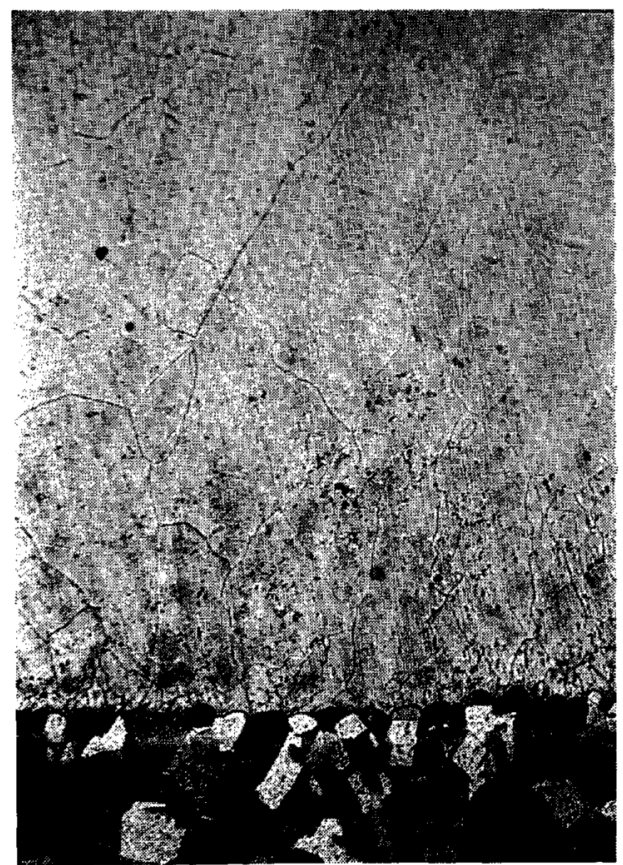

Photo. $6 \mathrm{Cu}-\mathrm{Sn}$ diffusion couple, $780^{\circ} \mathrm{C}$ for $1 \mathrm{hr}$ then reheated. to $803^{\circ} \mathrm{C}$ and quenched. $(\times 100)$

Photo. 5 and Photo. 6 show the microstructures of specimens, which were kept isothermally both at $780^{\circ} \mathrm{C}$ for 1 hour and heated to $798^{\circ} \mathrm{C}$ and $803^{\circ} \mathrm{C}$. respectively at the rate of $10^{\circ} \mathrm{C} / \mathrm{min}$ and subsequently quenched in water. As shown in Photo. $5, \beta$ decomposes to $\alpha$ and liquid at the peritectic temperature, increasing the interface of the solid and liquid. However, Photo. 6 shows the decreased interface between $\alpha$ 
and liquid, and there can be seen only two layers of $\alpha$ and liquid. Consequently it is confirmed that the remarkable acceleration of dissolution at the peritectic temperature is caused by the increment of the interface between solid and liquid produced by the peritectic decomposion.

\section{Reduction of the abnormal expansion}

\section{(1) Isothermal sintering just below the peritec-} tic temperature

Since the amount of the abnormal expansion decreased parabolically with a decreasing heating rate as shown in Fig. 4, slow heating is a good method to reduce the expansion. However, in this experiment isothermal sintering just below the peritectic temperature was examined.

Coexisting with the solid $\mathrm{Cu}(\alpha)$, the $\beta$ and the liquid phases just below the peritectic temperature, slow diffusion of $\mathrm{Sn}$ atoms during isothermal sintering from the liquid alloy to solid $\mathrm{Cu}$ through the $\beta$ phase is expected to give a gradual reduction of the liquid phase in the compact, in other words gradual increment of solid phase in it, where the similar effect of slow heating as described above may be obtained.

From this point of view, the same specimens as mentioned above, were placed respectively in the dilatometer and heated constantly at the rate of $20^{\circ} \mathrm{C} /$ min up to $735^{\circ} \mathrm{C}, 760^{\circ} \mathrm{C}$ and $785^{\circ} \mathrm{C}$ respectively, after isothermal keeping at these temperatures the specimens were reheated at the same rate $20^{\circ} \mathrm{C} / \mathrm{min}$.

The amount of abnormal expansion obtained in this manner is graphically shown in Fig. 11 in relation to the isothermal keeping time at $735^{\circ} \mathrm{C}, 760^{\circ} \mathrm{C}$ and $785^{\circ} \mathrm{C}$ respectively.

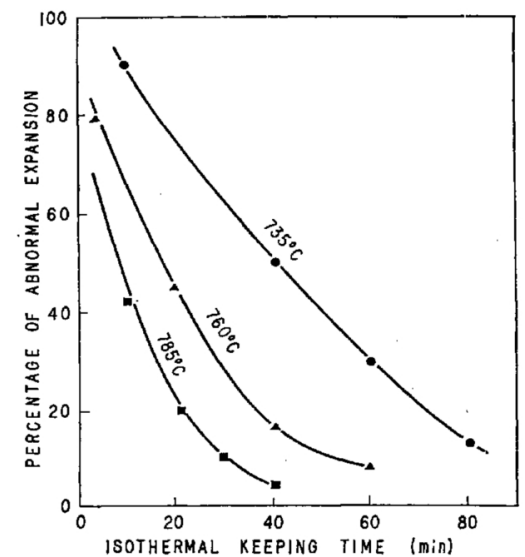

Fig. 11 Decrement curve of the abnormal expansion vs. the isothermal keeping time.

The abnormal expansion decreases with increasing isothermal keeping time, and this decrement increases with increasing isothermal heating temperature. When the logarithm of the isothermal keeping time for a half decrement of abnormal expansion was plotted against the reciprocal of the absolute temperature as shown in Fig. 12, a linear relationship was obtained.

(2) Reduction of the Sn content in Cu-Sn powder compacts

Under the same heating conditon the quantity of liquid phase retained in the $\mathrm{Cu}-\mathrm{Sn}$ compacts during sintering up to $798^{\circ} \mathrm{C}$ is to be expected to decrease with reduction of the original $\mathrm{Sn}$ content in green compacts, and the following abnormal expansion will also decrease.

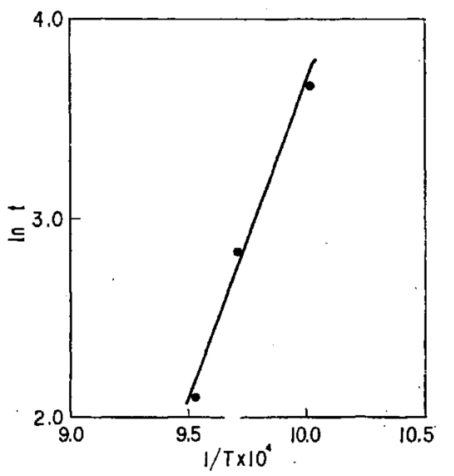

Fig. 12 A plot of the logalithm of $t$, isothermal keeping time for the half decrement of the abnormal expansion, vs. the reciprocal of the absolute temperature.

Fig. 13 shows a dilatometric curve of a $8 \%$ Sn containing compact in comparison with that of the 10 $\% \mathrm{Sn}$ containing previous specimen. The abnormal expansion of the former is reduced by $55 \%$ of the latter.

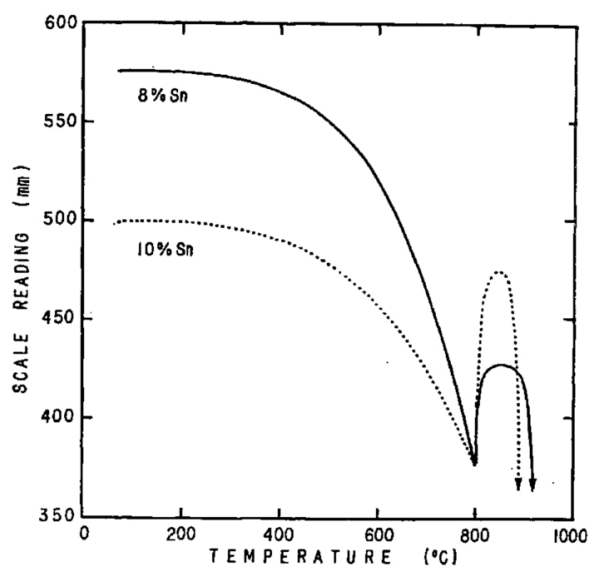

Fig. 13 The effect of the Sn-content on the abnormal expansion for $\mathrm{Cu}-\mathrm{Sn}$ compacts.

\section{(3) Atmosphere controlling}

As an immediate cause of the abnormal expansion the evolution of gases should be considered to originate from those which have adhered previously on the surfaces of the powder particles or been absorbed in the liquid phases from the sintering atmosphere, where some decomposed gases of the lubricant may have been included.

To compare the above obtained curve of full abnormal expansion, the specimens compacted without lubricant were also examined. Since all the examination had been carried out only in anhydrous cracked ammonia, as a comparison different experiments were carried out in pure $\mathrm{N}_{2}$ and vacuo respectively. However, the heating rate for the dilatometric examination was held constantly at $20^{\circ} \mathrm{C} / \mathrm{min}$.

In Table 2 abnormal expansions in different atmospheres are compared with one another, where the 
reading of abnormal expansion obtained from the experiment in cracked ammonia for the specimen compacted with lubricant was counted in 100 .

Owing to scattering of the data, the effect of the sintering atmosphere on the abnormal expansion could

Table 2 Comparison between abnormal expansions in different atmospheres.

\begin{tabular}{c|c|c}
\hline Specimen & $\begin{array}{c}90 \% \mathrm{Cu}+10 \% \mathrm{Sn} \\
0.5 \% \mathrm{Zn}-\mathrm{st}\end{array}$ & $\begin{array}{c}90 \%+10 \% \mathrm{Sn} \\
\text { non-lubricant }\end{array}$ \\
\hline Ctmosphere & 100 & 79 \\
Cracked $\mathrm{NH}_{3}$ & 62 & 45 \\
Pure $\mathrm{N}_{2}$ & 52 & 52 \\
Vacuo & & \\
\hline
\end{tabular}

not be determined exactly. However, approximately, $40 \%$ of the full abnormal expansion seems to originate in the sintering atmosphere of $\mathrm{H}_{2}$, another $40 \%$ of it to be generated from the gas originally absorbed in the compacts or adhering on the surfaces of particles, and the rest of $20 \%$ from the decomposed gas of lubricant.

Possibly $\mathrm{H}_{2}$ can be considered as the reason for abnormal expansion, since it is well known that the most absorbable gas in molten metals and alloys is $\mathrm{H}_{2}$. Consequently, $\mathrm{H}_{2}$ free sintering atmosphere is available to reduce abnormal expansion.

\section{Discussions}

On sintering of the $\mathrm{Cu}-\mathrm{Sn}$ powder compacts, the $\mathrm{Sn}$ particles begin to melt above the melting point of $232^{\circ} \mathrm{C}$, and the melting regions enrich their $\mathrm{Cu}$-content along the liquidus line of the $\mathrm{Cu}-\mathrm{Sn}$ equilibrium diagram with rising temperature, enlarging their domain at the same time, where the Cu particles don't diffuse directly into the melting regions, but form intermediate phases (intermetallic compounds) conjugated with thc melting regions, which are enriched in $\mathrm{Cu}$ content by melting of the intermediate phases along the liquidus line with rising temperature. Between $755^{\circ} \mathrm{C}$ and $798^{\circ} \mathrm{C}$, however, only one intermediate phase of $\beta$ exists in the compacts and disappears above the peritectic temperature of $798^{\circ} \mathrm{C}$.

As shown in Table 1 , the alloying region at $780^{\circ} \mathrm{C}$ contains both $\beta$ and melt, while the $\beta$ phase layer exists in the interface between $\alpha$ and melt as shown in Photo. 4. Since the total content of $\mathrm{Sn}$ in the green compact was $10 \%$, the final phase of the compact should be only $\alpha$ after concentration leveling. Illustrate the local diffusion in the compact just below. $798^{\circ} \mathrm{C}$, as shown in Fig. 14, the rate of diffusion should be determined by the slower movement of $\mathrm{Sn}$ atoms in the solid phase of $\alpha$ and $\beta$, where the slow rate of diffusion can be seen during sintering. On rapid heating, a large amount of liquid phase retains in the compact owing to the delay of concentration leveling. At $798^{\circ} \mathrm{C}$, however, the peritectic decomposition of $\beta$ gives a direct contact between $\alpha$ and liquid in the compact enlarging the interface of them, where the retained liquid phase is almost consumed by the remarkable promotion of diffusion between $\alpha$ and liquid. In this manner, the rapid solidification is given by the concentration leveling action at this: temperature, as shown in Photo. 2 and Table 1. Since the liquid phase can absorb rapidly gases and be: easily saturated with them, the absorbed gases in the: retained liquid phase are suddenly exhausted by the

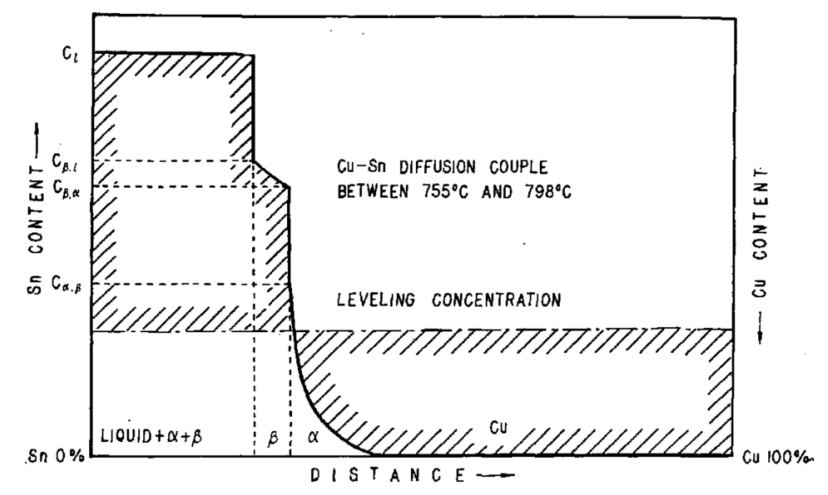

Fig. 14 Illustration of $\mathrm{Cu}-\mathrm{Sn}$ diffusion couple between $755^{\circ} \mathrm{C}$ and $798^{\circ} \mathrm{C}$.

rapid solidification at the peritectic temperature of $798^{\circ} \mathrm{C}$, showing the abnormal expansion, where the concerned gas may be estimated principally as $\mathrm{H}_{2}$ from the atmophere controlling experiment above described.

The amount of the retained liquid phase in the: compact depends upon the proceeding of diffusion (concentration leveling) as mentioned above, therefore: the amount of the abnormal expansion may indicate the proceeding of diffusion just below the peritectic temperature of $798^{\circ} \mathrm{C}$. From the linear relationship. in Fig. 12, the abnormal expansion may be subject to the law of diffusion, where the calculated activation. energy of $68 \mathrm{kcal} / \mathrm{mol}$ is about 2 times as that for the diffusion of $\mathrm{Sn}$ in $\alpha$ solid solution of $\mathrm{Cu}-\mathrm{Sn}$ system. Such a large value may depend upon the diffusion in $\beta$ phase, or be affected by other factors.

\section{Conclusions}

Results obtained were as follows :

(1) The abnormal expansion appears always at the peritectic temperature of $798^{\circ} \mathrm{C}$ during sintering for $\mathrm{Cu}$-Sn compacts. However, it never appears below this temperature.

(2) Sn rich liquid phase retained in the compact grows in amount along the liquidus line of the $\mathrm{Cu}-\mathrm{Sn}$ equilibrium diagram with increase of heating temperature, and solidifies rapidly just at the peritectic temperature.

(3) At this temperature the peritectic decomposition of the $\beta$ phase into solid $\alpha$ and liquid enlarges the contact surfaces between solid and liquid, and this promotes dissolution and diffusion of $\mathrm{Sn}$ into $\mathrm{Cu}$, thus. the rapid solidification takes place consequently.

(4) Upon rapid solidificatioin at this temperatuer the absorbed gas in the liquid phase abruptly evolves. out showing the abnormal expansion.

(5) The evolved gas can be estimated as $\mathrm{H}_{2}$.

How to eliminate the abnormal expansion can be written as follows :

(a) Slow heating rate during sintering.

(b) Isothermal sintering just below the peritectic temperature. 
(c) $\mathrm{H}_{2}$ free sintering atmosphere, such as $\mathrm{N}_{2}$, inert gases and vacuo.

(d) Reduction of the $\mathrm{Sn}$ content in $\mathrm{Cu}-\mathrm{Sn}$ green compacts.

(e) Promotion of diffusion by using $\mathrm{Cu}$ and $\mathrm{Sn}$ powders having a very fine particle size.

These methods mentioned above are useful in preventing abnormal expansion.

Acknowledgement

The author wishes to acknowledge the support given by the Sumitomo Electric Ind. Ltd., and he is especially grateful to Mr. Haruo Kubota, manager of the Itami Research Division for providing the research facilities and for his helpful discussions, and also wishes to thank Mr. Nobuyoshi Kubota, Mr. Michihiro Kato and Mr. Takeyoshi Soejima for their help in the experimental work, and also to Dr. Keiichiro Shoji, Osaka University, for his kindness in provide the author with many useful references. 